Canadian Journal of Higher Education Revue canadienne d'enseignement supérieur

Volume 48, No. 1, 2018, pages 118 - 131

\title{
Living the Curriculum Review: Perspectives from Three Leaders
}

Jennifer Lock

University of Calgary

Laurie Hill

St. Mary's University

Patti Dyjur

University of Calgary

\begin{abstract}
A requirement for quality assurance is becoming more prevalent in higher education today as institutions are being asked to demonstrate that they are providing robust, meaningful learning experiences for students. Many institutions are adopting curriculum review frameworks as part of their overall quality assurance strategy. Three leaders at various levels who were engaged in a year-long curriculum review process share reflections about their experiences and challenges while conducting an undergraduate program review. Their theoretical framework for an effective curriculum review process is shared in this paper. The leaders offer institutional, faculty, and course level insights, and make five recommendations for a collaborative curriculum review process: (1) setting clear expectations; (2) maintaining open, consistent communication; (3) incorporating multiple levels of leadership; (4) engaging various groups of stakeholders; and (5) implementing through actionable items.
\end{abstract}

\section{Résumé}

L'assurance qualité est de plus en plus répandue dans l'enseignement supérieur aujourd'hui, car les établissements sont invités à démontrer qu'ils fournissent des expériences d'apprentissage solides et significatives 
aux élèves. De nombreuses institutions adoptent des cadres d'examen des programmes d'études dans le cadre de leur stratégie globale d'assurance qualité. Un exemple de processus d'examen du curriculum est partagé dans cet article. Trois dirigeants de différents niveaux, qui ont participé à un processus d'examen du curriculum de quatre ans, partagent des réflexions sur leurs expériences et les défis liés à l'examen d'un programme de premier cycle. À l'aide de leur point de vue, cinq recommandations sont proposées pour un processus collaboratif d'examen du curriculum: (1) fixer des attentes claires; (2) maintenir une communication ouverte et cohérente; (3) intégrer plusieurs niveaux de leadership; (4) mobiliser divers groupes d'intervenants; (5) et mettre en œuvre des mesures.

\section{Introduction}

Increasingly, higher education institutions are being asked to demonstrate that their programs are effective, well-sequenced, and aligned, offering students a high quality learning experience. Stakeholders require evidence of quality, and quality improvement, with regard to student learning. While the notion of quality is not new (Elassy, 2015), contemporary higher educational institutions are now giving greater priority to quality assurance measures. One strategy for quality assurance is the implementation of a curriculum review at the program level. The curriculum review provides a documentation of alignment and misalignment with regard to program goals, learning outcomes, instructional strategies, and assessment. An evaluation process such as this can lead to action plans that guide next steps in improving the quality of teaching and learning experiences. Institutions preparing to develop quality assurance frameworks that may include curriculum review processes and structures to address quality assurance or what Biggs and Tang (2011) refer to as "quality enhancement-of teaching and learning" (p. 4), can look to authorities such as Diamond (2008) and Desha, and Hargroves (2014) for guidance.

The purpose of this paper is fourfold: (1) to provide an overview of collaborative curriculum review process as part of quality assurance; (2) to share the curriculum review process used at a Canadian university and discuss guidelines for this work; (3) to convey how the theoretical framework has informed the process and the impacts on our own professional practice as academic staff; and (4) to share recommendations for a collaborative curriculum review process. We are reporting on our leadership experiences in our specific context and appreciate that these experiences are not directly transferable to other institutions, programs, or contexts.

We use Schön's (1983) work on reflection in this paper to examine our experiences and expertise as three academic staff members who had different leadership roles (institutional, faculty, and course level) as part of our undergraduate program curriculum review process. At the institutional level, the curriculum development specialist's role was to provide information needed to conduct the review, offer guidance, facilitate workshops and curriculum discussions, and provide feedback. At the faculty level, the associate dean of teaching and learning worked with academic staff to co-facilitate the curriculum review process. At the course level, a course coordinator was responsible for leading the review process with instructors for their particular course offering. 


\section{Overview of the Collaborative Curriculum Review}

Quality assurance of academic programs is of increasing importance as higher education institutions are asked to demonstrate that they are providing relevant and effective learning experiences to students, especially considering the rapid growth many universities are experiencing in order to meet the demands (Uvalic-Trumbic, 2016). One mechanism that is being used to bridge quality and accountability is that of curriculum review. The curriculum review process uses multiple sources of evidence to visualize elements of the curriculum, including learning outcomes, teaching and learning activities, and student assessments. A curriculum review is a formative evaluation process and an "academic staff-led critical examination ... for the purpose of optimizing the learning outcomes of that program" (University of Calgary, 2015, p. 2).

Part of such a review involves mapping the curriculum, which is a process of associating course outcomes with program-level learning outcomes, aligning elements of courses within a program, and ensuring that the map reveals a strategic structure that enhances student learning (Harden, 2001). Mapping the curriculum captures and represents curricular data in charts and graphs so that reviewers can identify associations and alignment, locate gaps and redundancies, and examine strengths and trends (Robley, Whittle, \& Murdoch-Eaton, 2014).

The effectiveness of each course depends on clarity of purpose, compelling learning experiences, and appropriate assessment strategies. Additionally, each course must fit into the program as a whole, connecting to other courses in a way that scaffolds student learning (Kaupp \& Frank, 2014). Disconnects can occur when course goals and learning experiences are treated in isolation and when instructors are not fully aware of what other members of their group are doing or teaching. In addition to the design and implementation of courses, wider faculty supports must be in place to ensure a positive learning environment and a meaningful disciplinary experience for students (Zelenitsky et al., 2014).

Through the mapping process, alignments and gaps are revealed. A collaborative curriculum review process employs other tools as well as the mapping; all academic staff are given the opportunity to engage in thinking critically about their course planning and instruction. We also used the tools of multiple data sources, and guided discussions and reflection. The goal was that the curriculum review would provide evidence as to whether students were able to acquire deep conceptual links between theory and practice. Our curriculum review would identify areas requiring attention so we could improve student learning opportunities. It would also provide academic staff with greater clarity about program goals and coherence.

Instructors who have been involved in a collaborative curriculum review process have noted that there are various benefits to such an approach. According to Zelenitsky et al. (2014), involving instructors in a curriculum review creates a common language in the faculty for discussing curriculum-related topics. Lam and Tsui (2013) note that people who engage collaboratively in curriculum reviews can benefit through a deeper understanding of the curriculum and have the opportunity to reflect on the implicit assumptions they've made about it. Through discussion, they can share what is going on in their courses, talk about pedagogical practices, gain ideas, and identify similarities and differences between courses (Uchiyama \& Radin, 2009). According to Kaupp and Frank (2014), the review 
process can result in a huge amount of complex data, which is best understood collectively by those who are involved in it. Collaborative discussion and decision-making promote understanding; can lead to more specific, contextualized research findings; foster a shared responsibility for the curriculum; and strengthen commitment to positive changes (Kaupp \& Frank, 2014; Kelly, 2009; Oliver \& Hyun, 2011).

\section{Our Institutional Curriculum Review Process}

In 2013, our university launched the implementation of the Academic Quality Assurance Handbook: Curriculum Reviews. It was noted in the document that quality improvement occurs "through a focus on setting goals, measuring performance, and periodically re-evaluating the core mission at multiple levels of the University academic enterprise" (University of Calgary, 2015, p. 2). A critical component of this work is the curriculum review process that focuses on the quality of the curriculum offered per degree program, which is mandatory for all undergraduate programs and course-based graduate programs.

In consultation with the curriculum development specialist and administrators of the program (e.g., associate deans and course coordinators), a framework is established that aligns to the academic quality assurance document, but is customized for the needs of each program. For example, each group defines specific inquiry questions that will guide data collection, analysis, and recommendations for action. The university's curriculum development specialists can offer leadership, guidance on process, and resources. Although the review process results in a report, it outlines an action plan that the group will implement over a five-year period, making the review a continuous improvement process as opposed to a summative evaluation.

In 2013-14, our School of Education engaged in the evaluation of the undergraduate program. The Curriculum Review Team was co-led by the associate dean of teaching and learning and the university's curriculum development specialist. The team was also composed of the associate dean of the undergraduate program and course coordinators for each of the multi-section courses. This team was responsible for leading the curriculum review process, analyzing the data, and creating a final report. Numerous meetings occurred at various levels (e.g., course coordinators working with instructional teams).

The curriculum review process was inquiry-based and evidence-informed. At the start, the Curriculum Review Team engaged in a collaborative discussion to identify nine critical questions to guide the examination of the curriculum during the review process. Questions required people to examine the alignment, gaps, and redundancies between the program-level learning outcomes, competencies, and course outcomes and assignments; scope and sequence of courses in the program; semester theme alignment with program-level learning outcomes; vision of the program; and the intended, delivered, and experienced curriculum. Such questions required evidence to be gathered to address concerns, such as how well the program goals were reflected in courses and assignments, to what degree the new Alberta Education Competencies were being met in the program, and whether there were any conflicts in approaches or philosophies used that were impacting the integrity of the program (Faculty of Education, 2014). Through the following five-prong data collection approach and consultation with students, partner- teachers, and academic staff, the Curriculum Review Team identified a number of strengths and directions for future work. 
First, the curriculum development specialist and associate dean created a standard curriculum mapping process. A major component of the process required course coordinators to engage in a course mapping exercise with instructors that involved mapping program-level learning outcomes to provincial competencies, mapping course outcomes to teaching and learning activities and student assessments, as well as identifying the level (introduced, competency, or advanced) to which the course outcomes were addressed. Once the mapping was completed at the course level, the curriculum team (including course coordinators, associate deans, and the curriculum development specialist) carried out a focus group analysis of the curriculum mapping data, and guiding questions were used as a means to interpret the findings.

Second, a short survey was distributed by the associate dean's office to all students in the final year of the program asking them to share their perceptions with regard to such items as scope and sequence of the course, depth of coverage of content/topics, and how well the program prepared them for future employment.

Third, the associate dean's office sent a survey to partner-teachers in the schools asking specific questions focused on curriculum sequencing, scope of the program, and curriculum alignment.

Fourth, the curriculum development specialist and the associate dean worked with the standard reports generated from the Office of Institutional Analysis that included information such as enrolment, attrition, retention, fail/withdraw statistics, and completion rates and times.

Fifth, the curriculum review specialist, along with the associate dean, facilitated a halfday consultation session. All academic staff, including the course coordinators, received a draft of the report and were asked to analyze the data. The purpose of the meeting was to gain feedback and recommendations.

\section{Results of the Curriculum Review}

The Faculty of Education's (2014) action plan provided the associate dean of the undergraduate program with next steps in terms of program enhancement. A number of recommendations were identified in the action plan, along with the timeline for implementation over five years. In addition, lead responsibility was also allocated to specific individuals or teams. For the purpose of this paper we have selected three recommendations to provide an example of the nature of the next steps that emerged from the review.

Recommendation 1: Have students develop an e-portfolio. A student e-portfolio would be used across the program to evidence student work over time, creating connections between courses and practicum experiences. A working group was established to identify how different course assignments could contribute to the portfolio. Resources were allocated to provide support to assist students in creating the e-portfolios and to help academic staff in supporting students in developing them. Further, instructional resources were created and posted to a website to help individuals in creating their e-portfolios.

Recommendation 2: Address short- and mid-term student assessment action items. Careful attention was to be given to how assessment was being enacted in all courses in the program. Specialization course coordinators led this work with their instructional teams. Also, a decision was made to shift the assessment course from the final semester to an earlier point in the program. Different data sources pointed to the need to 
incorporate learning about assessment earlier in the program in order to foster greater linkages between specialization courses and the practicum experience. The need for ongoing purposeful conversations among instructors with regard to embedding formative assessments into more courses also emerged from the data (Faculty of Education, 2014).

Recommendation 3: Continue to provide support for the use of signature pedagogies (Shulman, 2005). Academic staff were encouraged to design courses using one or more signature pedagogies in engaging student learning. To support them, educational development sessions were offered to help foster greater understandings of signature pedagogies, and design/facilitate them within the undergraduate programs (Faculty of Education, 2014). Through the Office of Teaching and Learning, there have been increased educational development opportunities and greater access to signature pedagogy resource materials.

Figure 1 provides a framework that identifies elements and processes that occurred as part of the curriculum review process for quality assurance. The outer circle describes the stages of the curriculum review process beginning with establishing the Curriculum Review Team, identifying guiding questions to support the process, visioning and articulating learning outcomes, identifying data sources and engaging in data collection, analyzing the findings and discussion of significances in relation to the guiding questions, writing a final report, and implementing the action plan. The inner circle captures the iterative and continuous nature of how ongoing discussion leads to program improvement through the evidence-driven process.

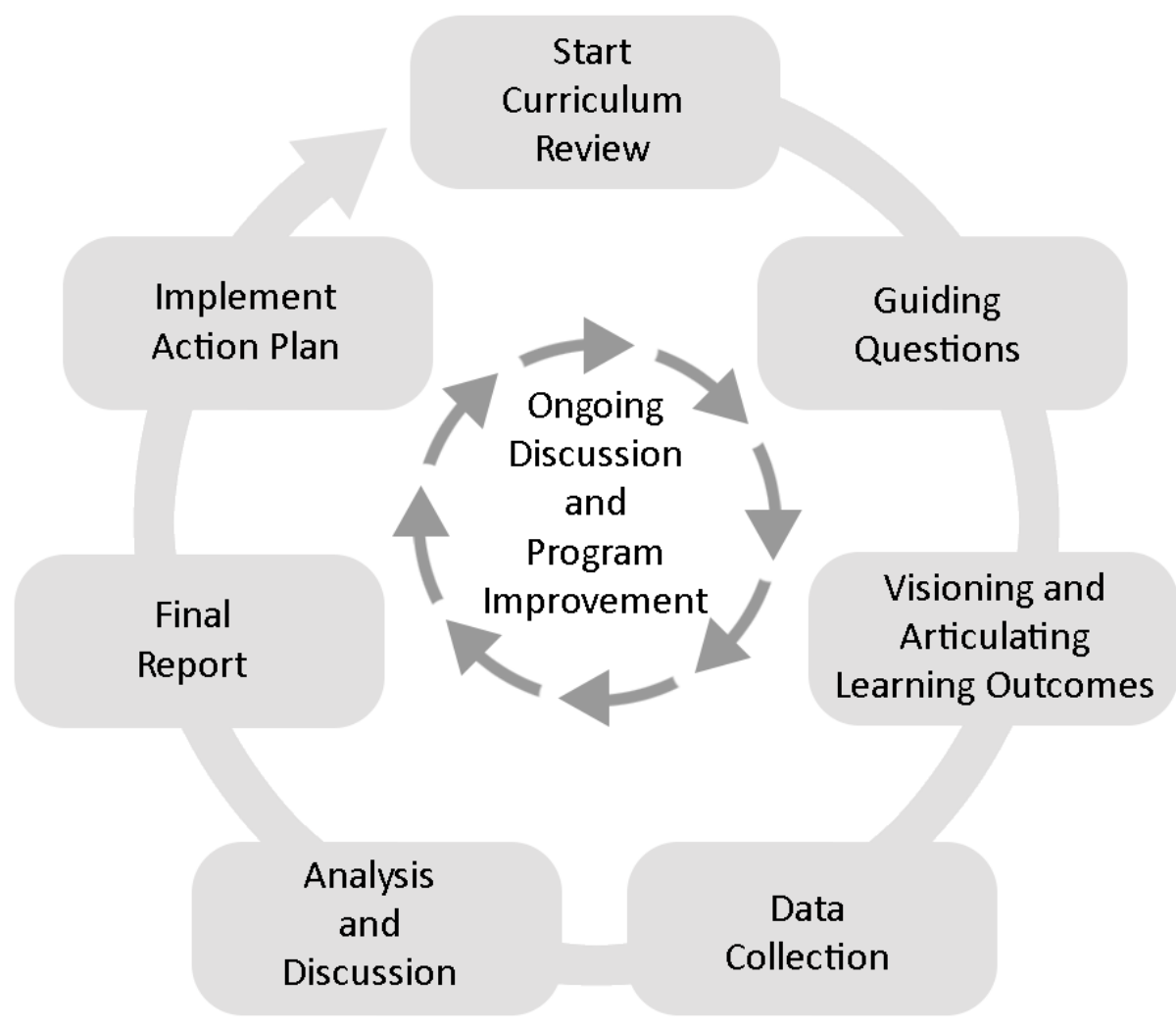

Figure 1: Elements of the curriculum review process for quality assurance (Dyjur, 2016) 


\section{The Theoretical Framework}

Reflection plays an important role during and after a curriculum review process. This paper is grounded in our reflections that are centred on our professional practice and experience with this curriculum review. To frame the reflective process, we have drawn on Schön's (1983) notion of reflection-in-action and reflection-on-action. Reflection is about conducting "an experiment which serves to generate both a new understanding of the phenomenon and a change in the situation" (Schön, 1983, p. 68). In this case, the phenomenon is the multiple levels of leadership required in conducting a program curriculum review. Through our reflections, we have gained new understandings of distributed leadership and factors that impact the required collegial dynamic for a successful review process.

Reflection-in-action involves purposefully examining our actions and experiences during the review process and becoming informed of our next steps. At each stage of the curriculum review process, the curriculum development specialist, the associate dean, and the course coordinator engaged in various forms of reflection-in-action. For example, a debrief occurred by the curriculum development specialist and the associate dean after each curriculum team meeting and/or workshop that was designed to identify what worked well, to modify based on feedback, and to establish the next course of action to continue moving the review forward in a timely manner.

The focus on the next section is on reflection-on-action (Schön, 1983). Once the curriculum review was completed, the curriculum development specialist, the associate dean, and a course coordinator met at various times to discuss their experiences and to identify how these impacted their personal and professional practices. In writing this paper, we have contemplated next steps in terms of the nature of our leadership, as well as the work involved in enacting a program curriculum review.

\section{Impact on Professional Practice}

Through our leadership at the institutional, program, and course levels, we led the engagement in the process in various ways. Given each of our unique experiences with the curriculum review, we gained new insights that have impacted our professional practice as academic staff in support of quality assurance. In the following section, we each share key learnings gained from the experience.

Insights from the curriculum development specialist at the institutional level. One thing I learned while working on this project was the importance of conveying expectations and setting the right tone at the beginning of the review. Some people had misconceptions about the review process. For example, some thought that the review committee would be doing all the work of the review, rather than having broad participation and discussion. I laid the groundwork on subsequent projects by introducing curriculum review to all faculty, outlining different roles and opportunities to participate, answering questions, and addressing concerns.

I also learned that there are many factors that impact a curriculum review, including time and budget, leadership, energy, and fatigue. The trend is for institutions to mandate more accountability and quality assurance processes than ever before (Uvalic-Trumbic, 2016). While there are benefits to such processes, they also increase expectations placed on faculty members. It is understandable that, occasionally, there is waning enthusiasm 
and fatigue associated with review processes, as well as an ebb and flow in the work. Strong leadership can be instrumental in overcoming such challenges. In subsequent projects, I have worked closely with review leads to identify potential barriers and ways to address them. Otherwise, the project will fade once the report has been completed and the important work of enhancing the curriculum will be forgotten.

Another thing I learned was that ongoing communication and opportunities for collaboration greatly enhance the results of a review. During the process, groups discuss what matters to them about a program, what they want to know about it, and how students experience it. Through these discussions, they uncover implicit assumptions and gain new perspectives about the curriculum. Leaders of the review also need to be open and explicit about the review process. Such an approach can foster investment in the process and ensure that there are opportunities for broad participation. Ongoing communication is essential since the action plan can take years to implement and offers many opportunities for collaboration, at regular faculty meetings, in working groups and ad hoc committees, and partnerships with students and other faculties.

Insights from the faculty level leader. In my role as the associate dean of Teaching and Learning, the undergraduate program was the first program for which I led a curriculum review. The process was rich with numerous learning experiences. One of the first things that I learned was the importance of communication. The curriculum review process required me to work carefully in articulating the processes, expectations, and structures in order to help instructional leaders (e.g., course coordinators) to effectively engage in the mapping and review processes. For example, as a group, we had to identify questions to guide our inquiry so as to gather the appropriate data in order to address our concerns. The process required me to communicate expectations for individual and large group work and to ensure timelines were met. Further, when sharing the findings from the review at a town hall meeting with academic staff who teach in the undergraduate program, it required the formation of questions to guide the conversations and to have recorders capture the discussions in order to use the data to inform the next iteration of the writing process. Overall, communication was key in informing members of the Curriculum Review Team of the work to be done and next steps, but also to keep all members of the faculty informed that the process was occurring.

The collegial conversations among course instructional teams, as well as with the Curriculum Review Team as they engaged with the data, resulted in a valuable learning experience. For example, when the Curriculum Review Team did a focused analysis of the data, they discussed the nature of the alignments that emerged from the mapping exercises, as well as the breadth and depth to which outcomes were being achieved. Through these conversations, insights were gained. As well, these experiences provided opportunity for a deeper understanding of not only the course(s), but also for how they connected in meeting the overall program goals. This led to the conversation about next steps and actionable items and carried with it an implicit ownership of the work. An important learning for myself was how to create the right balance in terms of leading the team meeting efficiently (e.g., moving things along) and providing adequate time and guided structure for collegial conversations.

With each step through this year-long journey, I questioned and gained new insights into the power of the curriculum review process in terms of affirming quality and setting 
the direction for program improvement. Through collaborative leadership and consultation with the faculty, the team generated a five-year action plan that has short-, medium-, and long-term actions with regard to curricular, programmatic, educational development, and administrative matters (Faculty of Education, 2014). This plan of action became the guide for the program. It provided a foundation for why and how changes needed to occur. The nature of the action plan moved the review from reporting on the status of the program (e.g., alignment, trends) to a road map for curriculum work for the next five years with identified leadership responsibilities to lead the various recommendations.

Insights from the course level leader. As an instructor in the Bachelor of Education program, I taught one of the first-year courses evaluated in the curriculum review process. For that course, my role as a field experience coordinator involved placing student teachers in classroom settings. As coordinator for these field experience courses, I was responsible for leading the mapping of them for the curriculum review. I was especially interested in seeing how the curriculum review would illuminate ways in which practicum experiences in the field connected to other courses on campus.

Participating in the curriculum review process allowed me to gain an understanding of the ways in which the foundational education course I taught and the field experience courses were linked to the content of other courses as well as to larger program goals and provincial competencies. Through conversations with other instructors and the curriculum review leaders, I had the opportunity to see how the overarching framework of the program design provided a valuable foundation for identifying and defining course goals, expectations, and competencies. For example, I developed a deeper understanding of how students experience the Bachelor of Education program through varied instructional activities, course assignments, timelines, and assessment strategies. These essential elements of course design have a cumulative impact on student experience that team members came to appreciate. Further, through discussion with my Curriculum Review Team colleagues, I was reminded of the importance of collaborating with each other in order to identify and define relevant and important course themes, teaching practices, and assessment strategies.

The process for our faculty's curriculum review was well planned and supported by our team leaders. However, there were challenges in carrying out the process. Gathering information from colleagues who taught field experience courses presented some obstacles. Many were sessional instructors who were not on campus on a regular basis, and so they were not readily available for or required to attend meetings. Without their participation, it was difficult to collect course data and achieve a broad understanding of how field experience courses were organized. As well, some field experience (practicum) instructors perceived a disconnection between what they taught and the more academic content courses taught within the program. They did not fully appreciate that their contribution to understanding how field experience courses were organized and implemented contributed an important perspective to our program review.

During my year of involvement in the curriculum review, I found that my individual commitment to the process was supported by the investment made by other group members. It was rewarding to be part of a team in an organized and supportive setting, in which productive dialogue with colleagues was enhanced and common goals were identified. As well, I learned that the clear, timely, and orderly leadership of the curriculum review lead- 
ers provided the tools and assistance that allowed us to focus on individual and collective tasks throughout the review process. Strong leadership was essential for open discussion to occur, so that future steps and recommendations could be formalized into an action plan.

Summation of the impact on professional practice. From reflection on our leadership and involvement in the curriculum review, we recognized the need for collaboration among faculty in order to fully understand a program's effectiveness. Our roles allowed us to appreciate our contribution to the program in a particular way, but engaging in the review process illuminated the importance of a collective understanding that could reinvigorate program philosophy, course alignment, and overarching program goals and learning outcomes. This understanding guided the team's plan of action for quality improvement.

To have a successful curriculum review, many people are required at various levels and commitments. A challenge for sustaining the review process is how to keep people engaged without fatigue setting in. How much can you ask of people in a review before it becomes overwhelming, or how can you anticipate that they are unable to allocate appropriate time to do the work that is required? As such, when working through a process, it is important to talk about expectations, time commitment, and responsibility so that people can establish manageable and acceptable workloads. During the review process, key leaders have a role to play in establishing and maintaining a balance between what is expected and what is achieved so as to not overwhelm or fatigue stakeholders. Key leaders should also consider how to delegate responsibility for various components as part of sharing the workload responsibility.

By reflecting on our experience, we have identified a number of strategies that support and sustain the work of a continuous improvement review, which is the core of our framework (see Figures 1 and 2). At the same time, we acknowledge that there are challenges and issues that emerge throughout the work that need to be attended to in a timely and professional manner in order to foster a healthy working dynamic. We conclude with a number of key strategies that are critical to supporting a collaborative curriculum review process that leads to meaningful and worthwhile results.

\section{Recommendations for a Collaborative Curriculum Review Process}

There is a need to foster a responsive pedagogical stance on curriculum review. By being conscious of and receptive to what has been identified in the curriculum review, individual instructors and leaders can create opportunities to engage in ongoing dialogue and an examination of the practice. As they engage in purposeful conversations, they gain a richer understanding and appreciation of the content, instruction, and assessment that is integral to achieving program goals. Structuring and scaffolding a responsive pedagogical culture creates a positive space for new and ongoing instructors to learn with and from each other. Fostering such a culture keeps the curriculum review alive and dynamic through the conversations, the pedagogical actions, and the reflections that then feed an informed iterative loop as a means of quality enhancement. Through our experiences in developing and fostering a collaborative and collegial culture for curriculum review, we offer the following five recommendations for administrators and academic staff: (1) set clear expectations; (2) have open, consistent communication; (3) incorporate multiple levels of leadership; (4) engage various groups of stakeholders; and (5) implement your findings through actionable items. 
(1) Set clear expectations. At the beginning of the curriculum review process, set clear expectations in order to provide a framework for working together. Expectations will guide and support the multiple steps involved in the review process and will allow the Curriculum Review Team to understand its role in mapping and in reviewing course design and program goals. Establishing vital steps to be taken in the curriculum review process and offering various committee members the flexibility to customize the process according to their needs is a beneficial strategy. In sharing a common process with clear expectations to guide the work, the Curriculum Review Team and its leaders can shape their work into a clear vision for teaching and learning within the faculty.

(2) Have open, consistent communication. During the entire curriculum review process, have open and consistent communication. Curriculum review leaders who articulate a strong rationale for the review process take the first step in creating trust among members of the Curriculum Review Team. Regularly scheduled meetings allow everyone to sustain commitment to the process and to develop their understanding of overarching program goals and teaching initiatives. While collaboration is important, the curriculum review leaders will be required to direct the team's conversation toward meaningful topics and goal-driven processes.

(3) Incorporate multiple levels of leadership. The process requires a clear understanding of who will lead it and take responsibility for the decisions that are made in regard to setting committee expectations and goals. The curriculum review leaders have responsibility for articulating the goals and framing the process for the curriculum review, while also engaging team members in the work. When the curriculum review leaders recognize team efforts and support difficult conversations, they create a credible and vibrant team with a common purpose. However, the curriculum review leaders also share the leadership role with team members. Course leaders, in their meetings with faculty colleagues, lead the collection of course data and are responsible for compiling information that could be shared with the team. This shared pattern of leadership offers opportunities for growth and professional development for all participants.

(4) Engage various groups of stakeholders. When students are invited to participate on the Curriculum Review Team, their presence lends integrity to the process. Students can also be surveyed as they can provide a unique perspective on how the program is experienced. Faculty and course instructors should be extensively consulted. Supporting course instructors in recognizing the value of a curriculum review and in sustaining their commitment to the process are the necessary steps for bringing about changes in practice and course design. The five-year action plan, an outcome of the curriculum review, is an important blueprint for course instructors in ensuring a consistent and ongoing enactment of course outcome and program goals.

(5) Implement your findings through actionable items. Implementation ensures that the work of the Curriculum Review Team is taken up and that their report is moved into actionable items. The report lays the foundation for a five-year plan that sets a direction for the actions to be taken with regard to curriculum, program goals, and professional development. Specific structures and opportunities should be formalized for instructors so that recommendations from the curriculum review are taken up in meaningful ways and studied so that others are informed on the next steps. A climate of support for implementation ensures that positive change can be carried out and sustained. 
We added a third dimension to the curriculum review framework in developing and nurturing a collaborative and collegial culture for the curriculum review (Figure 2). In Figure 1, the inner circle is focused on the ongoing discussion and program improvement that is a result of the curriculum review process (middle circle). The outer circle in Figure 2 includes five elements that influence the collaborative and collegial culture, exemplifying the values we hold about curriculum work: a need to establish clear expectations; open consistent communication throughout the review process; engagement of multiple levels of leadership (e.g., administrators, course coordinators, and instructors); invitation and engagement of various stakeholders into the process (e.g., academic staff, students, and partner-teachers); and the implementation of actionable items.

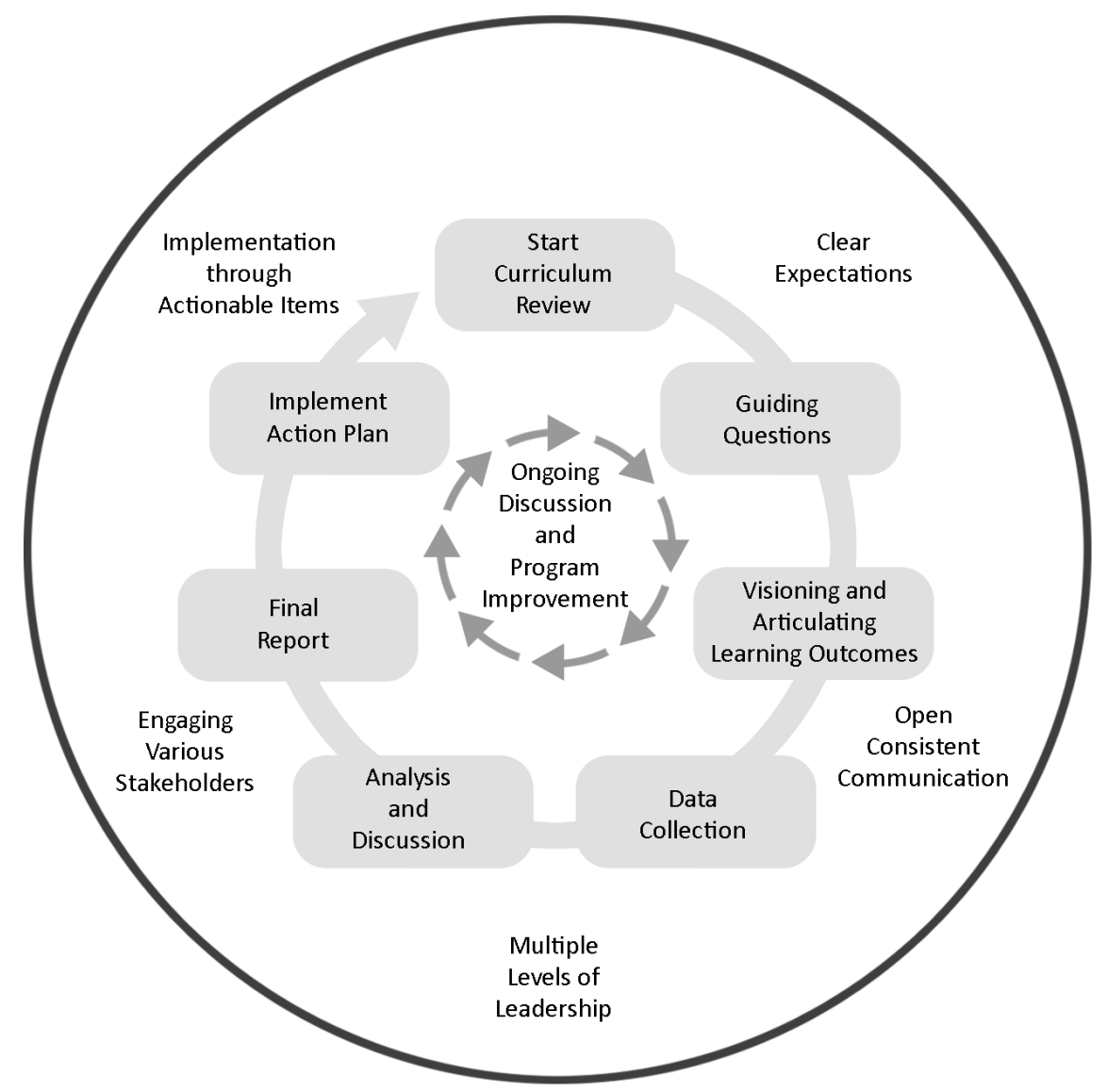

Figure 2. Framework for developing a collaborative culture for curriculum review

\section{Conclusions}

As increasing numbers of higher education institutions engage in quality assurance practices, structures and processes need to be implemented to engage people in the work. The curriculum review process articulates in a concrete way the expectations, alignments, and plans of action for quality improvement. The success of this collegial process requires leadership at all levels. 
Drawing on our different leadership roles and perspectives, we identified and reflected on what we learned during the curriculum review and the individual contributions that we made to the process. We concluded by sharing recommendations that support a collaborative, purposeful curriculum review process and strategies that foster greater engagement with the work. A critical component to the success of a curriculum review that nurtures a collaborative and collegial culture while ensuring high-quality, meaningful learning experiences for students is the development and sustainability of multiple levels of leadership.

\section{Acknowledgement}

The authors thank Ykje Piera, University of Calgary, for building the figures in this paper.

\section{References}

Biggs, J., \& Tang, C. (2011). Teaching for quality learning at university: What the student does (4th ed.). Berkshire, England: Society for Research into Higher Education \& Open University Press.

Desha, C., \& Hargroves, K. C. (2014). Higher education and sustainable development: A model for curriculum renewal. New York, NY: Routledge.

Diamond, R. M. (2008). Designing and assessing courses and curricula: A practical guide (3rd ed.). San Francisco, CA: Jossey-Bass.

Dyjur, P. (2016). Curriculum review process at the University of Calgary. Retrieved from http://curriculummapping.weebly.com/uploads/1/4/9/o/14908434/curriculum_ review_process_at_the_university_of_calgary_2016.pdf

Elassy, N. (2015). The concepts of quality, quality assurance and quality enhancement. Quality Assurance in Education, 23(3), 250-261. doi: 10.1108/QAE-11-2012-0046

Faculty of Education. (2014). Bachelor of Education curriculum review report: Executive summary. Retrieved from http://www.ucalgary.ca/provost/files/provost/ werklund_bed_curriculum_review_executive_summary_public_doc_july_2014_final. pdf

Harden, R. M. (2001). AMEE guide no. 21: Curriculum mapping: A tool for transparent and authentic teaching and learning. Medical Teacher, 23(2), 123-137.

Kaupp, J., \& Frank, B. (2014). Approaching the loop: A brief review of effective practises in continuous program improvement. Proceedings of the Canadian Engineering Education Association Conference, University of Calgary, Canmore, AB. Retrieved from http://ceea2014.files.wordpress.com/2014/06/ceea2014_submission_15.pdf

Kelly, A. V. (2009). The curriculum: Theory and practice. Los Angeles, CA: Sage Publications.

Lam, B., \& Tsui, K. (2013). Examining the alignment of subject learning outcomes and course curricula through curriculum mapping. Australian Journal of Teacher Education, 38(12). Retrieved from http://ro.ecu.edu.au/ajte/vol38/iss12/6

Oliver, S. L., \& Hyun, E. (2011). Comprehensive curriculum reform in higher education: Collaborative engagement of faculty and administrators. Journal of Case Studies in Education, 1-20. 
Robley, W., Whittle, S., \& Murdoch-Eaton, D. (2005). Mapping generic skills curricula: A recommended methodology. Journal of Further and Higher Education, 29(4), 321-330. doi: 10.1080/0309877050035342

Schön, D. A. (1983). The reflective practitioner: How professionals think in action. New York, NY: Basic Books.

Shulman, L. S. (2005). Signature pedagogies in the professions. Daedalus, 134(3), $52-59$.

Uchiyama, K. P., \& Radin, J. L. (2009). Curriculum mapping in higher education: A vehicle for collaboration. Innovative Higher Education, 33(4), 271-280.

University of Calgary. (2015). Academic quality assurance handbook curriculum reviews. Retrieved from http://www.ucalgary.ca/provost/activities/reviews

Uvalic-Trumbic, S. (Ed.) (2016). The CIQG international quality principles: Toward a shared understanding of quality. Council for Higher Education Accreditation. Retrieved from https://www.chea.org/userfiles/CIQG/Principles_Papers_Complete_web.pdf

Zelenitsky, S., Vercaigne, L., Davies, N. M., Davis, C., Renaud, R., \& Kristjanson, C. (2014). Using curriculum mapping to engage faculty members in the analysis of a pharmacy program. American Journal of Pharmaceutical Education, 78(7), 1-9.

\section{Contact Information}

Jennifer Lock

Werklund School of Education

University of Calgary

jvlock@ucalgary.ca

Jennifer Lock is the associate dean of Teaching and Learning and has been the specialization chair for the Learning Sciences in the Werklund School of Education. Her areas of specialization are in online learning, ICT integration, change and innovation, and educational development in higher education.

Laurie Hill is an assistant professor in the Department of Education at St. Mary's University. Her research interests include pre-service teacher education and specifically the connections between on-campus coursework and field practicum experiences. She is also interested in pre-service teacher professional identity, student transitions, and the variety of learning environments that support undergraduate student success. Dr. Hill can be reached at laurie.hill@stmu.ca.

Patti Dyjur, $\mathrm{PhD}$, is a curriculum development consultant with the Taylor Institute for Teaching and Learning, University of Calgary. She works with faculties and departments as they map, review, and assess their programs to identify strengths and areas for improvement, which she finds to be interesting and challenging. Her research interests include the impact of these curriculum review activities. Dr. Dyjur can be reached at pdyjur@ucalgary.ca. 